Fabrizio I. Scroppo, Elisabetta Costantini, Alessandro Zucchi, Ester Illiano, Francesco Trama*, Stefano Brancorsini, Felice Crocetto, Maria Rita Gismondo, Federico Dehò, Anna Mercuriali, Riccardo Bartoletti and Francesco Gaeta

\title{
COVID-19 disease in clinical setting: impact on gonadal function, transmission risk, and sperm quality in young males
}

https://doi.org/10.1515/jbcpp-2021-0227

Received July 31, 2021; accepted October 1, 2021;

published online October 29, 2021

\section{Abstract}

Objectives: We want to evaluate the possible presence of severe acute respiratory syndrome coronavirus 2 (SARSCoV-2) in semen samples and semen quality, looking for a possible relationship between the infectious disease and fertility.

Methods: In this prospective study, we enrolled 15 consecutive men (age 18-50 years) with positive

\footnotetext{
*Corresponding author: Francesco Trama, MD, Andrological and Urogynecological Clinic, Santa Maria Terni Hospital, University of Perugia, Viale Tristano di Joannuccio, 05100 Terni, Italy, Phone: 074420520, E-mail: francescotrama@gmail.com. https://orcid.org/ 0000-0001-9291-2426
}

Fabrizio I. Scroppo and Federico Dehò, Urology Department, Ospedale di Circolo, ASST Sette Laghi, University of Insubria, Varese, Italy. https://orcid.org/0000-0002-7281-8552 (F.I. Scroppo). https://orcid.org/0000-0002-0453-5710 (F. Dehò) Elisabetta Costantini and Ester Illiano, Andrological and Urogynecological Clinic, Santa Maria Terni Hospital, University of Perugia, Terni, Italy. https://orcid.org/0000-0001-9639-2886 (E. Costantini). https://orcid.org/0000-0001-5660-1815 (E. Illiano) Alessandro Zucchi and Riccardo Bartoletti, Department of Translational Research and New Technologies in Medicine and Surgery, University of Pisa, Pisa, Italy. https://orcid.org/0000-00032252-4297 (A. Zucchi). https://orcid.org/0000-0002-0021-0302 (R. Bartoletti)

Stefano Brancorsini, Department of Experimental Medicine, University of Perugia, Terni, Italy, E-mail: stefano.brancorsini@unipg.it

Felice Crocetto, Department of Neurosciences, Reproductive Sciences and Odontostomatology - Federico II University of Naples, Naples, Italy, E-mail: felice.crocetto@unina.it

Maria Rita Gismondo, Laboratory of Clinical Microbiology, Virology and Bio-Emergency Diagnostics, ASST Fatebenefratelli Sacco, Milan, Italy. https://orcid.org/0000-0001-6926-8660

Anna Mercuriali, Department of Medicine and Surgery, University of Insubria, Endocrine Unit, ASST dei Sette Laghi, Varese, Italy Francesco Gaeta, Surgical Department, Urological and Andrological Service, Military Hospital Centre of Milan, Milan, Italy oropharyngeal swab to SARS-CoV-2 and classified, according to WHO criteria, in mild to moderate disease. A semen sample was collected to detect SARS-CoV viral RNA by the automated Real-Time PCR ELITe InGenius ${ }^{\circledR}$ system and the GeneFinder ${ }^{\mathrm{TM}}$ COVID-19 Plus RealAmp Kit assay (ELITechGroup, France). Analysis of semen characteristics was performed according to WHO laboratory manual 5th ed. for the examination and processing of human semen. Blood samples for the dosage of hormonal assay, procalcitonin, interleukin 6, C-reactive protein were obtained. Results: SARS-CoV-2 RNA has not been detected in semen samples from any of the subjects analysed. Sperm analysis exhibited abnormal seminal values in 14 out of 15 patients (93.3\%). Furthermore, no difference was detected regarding sperm quality between mild and moderate SARS-CoV-2 patients. No alteration in the inflammatory indices was observed in the studied population, as well gonadotropins and testosterone levels.

Conclusions: COVID patients studied exhibits alteration of the seminal fluid both in microscopic and macroscopic characteristics such as hypoposia and increased viscosity, which have not been detected in previous studies. The presence of viral RNA within the seminal fluid was excluded.

Keywords: COVID-19; liquid semen analysis; male genital tract; SARS-CoV-2; spermatogenesis.

\section{Introduction}

The global coronavirus disease 2019 (COVID-19) pandemic has made it of primary importance to know all routes of transmission of the causative agent, severe acute respiratory syndrome coronavirus 2 (SARS-CoV-2) via bodily fluids data from the Italian Health indicate that approximately $26 \%$ of patients with COVID-19 have at least one pathology [1]. The SARS-CoV-2 virus has been reported in nasopharyngeal, nasal, and lower respiratory tract secretions [1]. It has also been detected in feces, urine and, at a lower infection percentage, in blood [2]. Little is known about the presence of 
the virus in semen or its ability to spread through sexual intercourse. It is known that in testis tissue and urogenital tract there are ACE 2 receptors capable of binding with the SARS-CoV-2 virus [3, 4]; however, the real presence and the role of SARS-CoV-2 in these sites is not clear and the few studies available on this topic show conflicting results.

Some authors have found the presence of the SARS-CoV-2 RNA in semen [5], others in the testis [6, 7]. In other studies, instead, it was found only in semen samples in a small percentage of patients in the acute stage of infection or in recovery [8], while in others it was not found in any patient [9].

The lack of homogeneity in the results could be due to the different research methodologies used (tissue or semen), the small samples analyzed, the different time elapsed from diagnosis to sample analysis, and the lack of standardization in the choice of the population included (asymptomatic or symptomatic, in acute or in remission stage).

However, knowing the presence of COVID-19 in sperm and any semen alterations is crucial in order to assess the possible sexual route for the transmission of the disease, including sperm donation by COVID-19 patients, and for further research focused on possible long-term consequences of the infection, like male infertility.

In the light of these considerations, the aim of our study was to evaluate the possible presence of SARS-CoV-2 in semen samples and to define the semen quality in sperm collected from young Italian men with COVID-19, confirmed through a nasopharyngeal swab.

\section{Materials and methods}

During the period September 2020-January 2021, 15 patients were enrolled at the External Wards Department of the Military Hospital Center of Milan, which is specifically set up for the hospitalization of military and civilian patients who have tested positive for COVID-19. All patients had a SARS-CoV-2 positive oropharyngeal swab. Adult males from 18 to 50 years old were included in the clinical study. Five out of 15 had fatherhood.

In relation to disease severity, the patients were divided into two groups (mild and moderate) according to the World Health Organization (WHO) "interim guidance" [10].

At the time of enrollment, the methods and purposes of the clinical study were explained to each patient, who signed a consent form and also filled in a dedicated form which included these data:

- past medical history, pharmacological history, and history of the present SARS-CoV-2 infection (date of the positive oropharyngeal swab, symptoms, and current therapy).

- social history (occupation, height, weight, body mass index (BMI), smoking, alcohol, and drug use).
We performed this study after obtaining institutional review board (IRB) approval n 41025 (University of Perugia - Italy).

\section{Blood sampling}

A blood sample was taken on the agreed day for the examinations, from each patient, early in the morning (by 08:30); it was sent to the San Carlo Hospital in Milan for the subsequent blood dosage of Follicle-stimulating hormone (FSH), Luteinizing Hormone (LH), testosterone, and inflammation index: procalcitonin (PCT), interleukin 6 (IL-6), and C-Reactive Protein (CRP).

Serum samples for measurement of LH, FSH, testosterone, IL-6, and PCT were detected by electrochemiluminescent immunoassays according to the protocol from the manufacturer (COBAS e602 Roche Diagnostics, Basel Switzerland). Serum CRP levels were measured using the immunoturbidimetric method on COBAS e702 (Roche Diagnostics, Basel Switzerland).

\section{Seminal fluid samples}

Each patient was also asked to collect, in the same morning at 10:00 am, a seminal fluid sample, which was used to perform, first, an analysis of semen characteristics (in accordance with the validated values in the WHO 2010) by a civilian consultant biology expert at the Military Hospital Center of Milan.

Spermogram: The sample was produced on-site by masturbation into a sterile plastic specimen cup following abstinence of 2-7 days according to WHO 2010. All subjects underwent semen analysis. The semen was left at room temperature for liquefaction for $30 \mathrm{~min}$. Once liquefaction took place they were moved into graduated and labeled test tubes.

A macroscopic evaluation was made to assess the following parameters: volume, $\mathrm{pH}$, color, liquefaction, and viscosity.

The liquefied semen samples were analyzed for sperm concentration and motility and were assessed under the light microscope at $200 \times$ magnification using Makler's counting chamber $\left(0.01 \mathrm{~mm}^{2}\right.$ and $10 \mu \mathrm{m}$ deep). Motility was scored manually, as percentages of fast forward progressive, slow forward progressive, nonprogressive, and immotile spermatozoa in 200 spermatozoa in at least five power fields per replicate.

Sperm morphology was assessed by staining samples with Diff Quick (MBT Medical Biological Technologies, Italy) according to WHO 2010 [11]. A vitality test was also made to identify immobile and nonvital spermatozoa.

The nonspermatic component was also evaluated: epithelial cells, red blood cells, leukocytes, and germ cells. The spermatogenic cells and leukocytes were evaluated in the staining. None of the analyzed samples had a leukocyte concentration greater than one million, such as not to assume an inflammatory response. The vitality of the spermatozoa was performed with the Eosin Y-Nigrosin test (Sigma-Aldrich). The spermatozoa were considered viable with the test $>58 \%$ according to the WHO 2010.

The remaining amount of seminal fluid was sent to the laboratory of Clinical Microbiology, Virology, and Bioemergency Diagnostics of the Sacco Hospital in Milan for immediate freezing and subsequent tests for the detection of the SARS-CoV-2 virus. 
RT-PCR: Molecular analysis was performed on available samples to detect viral RNA, using the automated Real-Time PCR ELITe InGenius ${ }^{\circledR}$ system and the GeneFinderTM COVID-19 Plus RealAmp Kit assay (ELITechGroup, France). The reaction mix was prepared manually, according to the manufacturer's instructions, and loaded on the system with other reagents, while RNA was extracted from $200 \mu \mathrm{L}$ of the sample and eluted in $100 \mu \mathrm{L}$; the final reaction volume consisted of $5 \mu \mathrm{L}$ of RNA plus $15 \mu \mathrm{L}$ of reagents mix. The RT-PCR profile was set up as follows, according to the manufacturer's instructions: $50{ }^{\circ} \mathrm{C}$ for $20 \mathrm{~min}, 95^{\circ} \mathrm{C}$ for 5 min plus 45 cycles at $95^{\circ} \mathrm{C}$ for $15 \mathrm{~s}$ and $58^{\circ} \mathrm{C}$ for $60 \mathrm{~s}$. Three target genes, RNA-dependent RNA polymerase (RdRP), Nucleocapsidprotein $(\mathrm{N})$, and Envelope membrane protein (E), have been simultaneously amplified and tested. A cycle threshold value (Ctvalue) lower than 40 was defined as a positive test result, according to the manufacturer's instructions.

To ensure the confidentiality of data, a serial number was assigned to each subject so that only the investigator was able to link a number to the corresponding person.

\section{Statistical analysis}

Continuous variables were presented as median values, and categoric data were presented as absolute or relative frequencies. Statistical analysis was performed using the Mann-Whitney U test to compare the variables. All calculations were performed using IBM-SPSS ${ }^{\circledR}$ version 22.0 (IBM Corp., Armonk, New York, NY, USA, 2013). A two-sided p-value $<0.05$ was considered significant.

\section{Results}

The average age of the 15 patients enrolled was 30 years. None of them had a history of co-pathologies that could interfere with the gonadal function; however, it should be noted that 11 of these patients were overweight (with a BMI between 25 and $30 \mathrm{~kg} / \mathrm{m}^{2}$ ), while only four were smokers and none were using alcohol or drugs. Demographic data are shown in Table 1.

Regarding the clinical course of SARS-CoV-2 infection, the symptoms reported by most patients were fever, headache, myalgia, rhinorrhea, ageusia, and anosmia; only two patients had gastrointestinal involvement, while three patients remained asymptomatic: 10 patients were classified as mild disease severity while five were moderate.

During hospitalization, no specific therapy (antivirals, antibiotics, chloroquine, or heparin) was administered, no one needed oxygen support; at home, they had been treated mainly with paracetamol, acetylsalicylic acid, protein supplements, and multivitamins.

In relation to the symptoms reported, it should be noted that the inflammation indices (PCR, pro-calcitonin, and IL-6) were normal in all patients.

Blood samples and semen collection were performed on average 8 days after the first positive oropharyngeal
Table 1: Demographic and clinical data of population.

\begin{tabular}{|c|c|}
\hline Data & COVID-19 ( $n=15$ patients) \\
\hline Age (mean $\pm S D$ ) & $30.6 \pm 8.7$ \\
\hline BMI (median, range) & $25.7(21.8-26.85)$ \\
\hline \multicolumn{2}{|l|}{ Hormonal determinations } \\
\hline $\begin{array}{l}\text { Testosterone, } \mu \mathrm{g} / \mathrm{mL} \text { (median, } \\
\text { range) }\end{array}$ & $6.51(2.9-8.5)$ \\
\hline FSH, U/mL (median, range) & $3.85(1.6-7.3)$ \\
\hline LH, U/mL (median, range) & $4.55(3-7.6)$ \\
\hline \multicolumn{2}{|l|}{ Indices inflammatory } \\
\hline Procalcitonin (median, range) & $0.03(0.02-0.05)$ \\
\hline Interleukin 6 (median, range) & 2 \\
\hline c-reactive protein (median, range) & $0.19(0.03-0.26)$ \\
\hline \multicolumn{2}{|l|}{ COVID-19 classification } \\
\hline Mild cases n, \% & $10(66)$ \\
\hline Moderate cases $n, \%$ & $5(33)$ \\
\hline Severe cases $\mathrm{n}, \%$ & 0 \\
\hline \multicolumn{2}{|l|}{ Symptoms } \\
\hline Fever n, \% & $3(20)$ \\
\hline Myalgia n, \% & $2(13.3)$ \\
\hline Anosmia n, \% & $6(40)$ \\
\hline Ageusia n, \% & $6(40)$ \\
\hline Rhinorrhea n, \% & $4(26.6)$ \\
\hline Cough n, \% & 0 \\
\hline Sore throat n, \% & 0 \\
\hline Dyspnea n, \% & 0 \\
\hline Diarrhea n, \% & 0 \\
\hline Hospitalization n, \% & $9(60)$ \\
\hline $\begin{array}{l}\text { Time between positive oropharyn- } \\
\text { geal swab and semen collection }\end{array}$ & $8.5 \pm 3.5$ \\
\hline \multicolumn{2}{|l|}{ Semen quality } \\
\hline Normal n, \% & $5(33.3)$ \\
\hline Oligozoospermia n, \% & $1(6.6)$ \\
\hline Asthenozoospermia n, \% & $2(13.3)$ \\
\hline Teratozoospermia n, \% & $4(26.6)$ \\
\hline Oligo-astheno-teratozoospermia & $1(6.6)$ \\
\hline \multicolumn{2}{|l|}{$\mathrm{n}, \%$} \\
\hline Oligo-teratozoospermia n, \% & $2(13.3)$ \\
\hline Sperm concentration, $10^{6} / \mathrm{mL}$ & $35,533,333 \cdot 33 \pm 20,968,911 \cdot 23$ \\
\hline Progressive motility & $42.13 \pm 14.25$ \\
\hline Sperm morphology & $4.06 \pm 1.70$ \\
\hline
\end{tabular}

swab for SARS-CoV-2 (range 0-25 days); at the time of collection, three patients had already returned negative on repeated swabs.

Regarding gonadal hormone function, all parameters (FSH, LH, and total testosterone) were normal, except for one patient who had borderline testosterone levels $(2.9 \mathrm{mcg} / \mathrm{L})$.

Semen analysis, considering sperm concentration, progressive motility, and morphology, was instead found altered in 13 out of 15 patients $(87 \%)$; in particular, progressive motility was reduced in 11 patients (73\%). Adding seminal volume as a parameter, hypospermia was found in four patients (27\%); in this perspective, one more patient 
needs to be added to the group with seminal alterations, bringing the total to 14 out of 15 (93\%).

Increased viscosity was also reported in 12 patients $(80 \%)$, with normal leukocyte counts in all collected samples. The viral RNA of SARS-CoV-2 searched for in the seminal fluid was not found in any of the patients (Table 2).

Therefore, taking all these parameters into account, only one patient did not show any significant alterations of the seminal fluid. This patient was 33 years old, overweight, a nonsmoker, and had manifested fever, neck pain, and diarrhea; at the time of collection, performed 11 days after the first swab, he was still positive for SARS-CoV-2. These clinical features were not different from the other patients. Moreover, even in patients who had declared to be asymptomatic, low sperm quality was found.

Finally, we did not find statistical differences in relation to the seminal parameters between the two groups of patients, those with mild or moderate symptoms (Table 3).

\section{Discussion}

It is well known that SARS-CoV-2 penetrates into human cells through a "spike" protein that is able to determine a structural modification of the outer membrane of infected cells, thus creating a way of entry into the host cell where it can replicate [12]. Furthermore, this spike protein has a high affinity for a special type of membrane receptors, which are the same receptors as the angiotensin-2 converting enzyme (ACE2r) which is expressed in multiple organ systems: this means that cells expressing these receptors could be the target of SARS-CoV-2 [13, 14]. However, coexpression of cellular protease TMPRSS2 is also required to penetrate inside cells [15].

In testis, ACE2r are present in spermatogonia, Sertoli cells, and Leydig cells, leading to conclude that there is an excellent tropism for the virus at the testicular level [3], potentially responsible for the damage to seminiferous tubule [13] and Leydig cells following infection. Recently,

Table 2: Spermiographic data.

\begin{tabular}{|c|c|c|c|c|c|c|c|}
\hline Patients $\mathbf{N}^{\circ}$ & Virological sperm test & Volume, $\mathrm{mL}$ & Viscosity & $\begin{array}{c}\text { Leukocytes, } \\
\text { million/mL }\end{array}$ & $\begin{array}{r}\text { Sperm concentration, } \\
\mathrm{m} / \mathrm{mL}\end{array}$ & $\begin{array}{r}\text { Progressive } \\
\text { motility }(a+b)\end{array}$ & $\begin{array}{r}\text { Normal } \\
\text { forms, \% }\end{array}$ \\
\hline 1 & NEGATIVE & 2.2 & Increased & 100,000 & $7,000,000$ & 5 & 2 \\
\hline 2 & NEGATIVE & 2.8 & Normal & 100,000 & $38,000,000$ & 30 & 4 \\
\hline 3 & NEGATIVE & 2 & Increased & 700,000 & $11,000,000$ & 30 & 2 \\
\hline 4 & NEGATIVE & 3.5 & Increased & 100,000 & $75,000,000$ & 15 & 2 \\
\hline 5 & NEGATIVE & 3 & Increased & 300,000 & $22,000,000$ & 40 & 3 \\
\hline 6 & NEGATIVE & 1.2 (hypoposia) & Increased & 100,000 & $44,000,000$ & 10 & 4 \\
\hline 7 & NEGATIVE & 3 & Normal & 500,000 & $58,000,000$ & 42 & 6 \\
\hline 8 & NEGATIVE & 1 (hypoposia) & Increased & 100,000 & $45,000,000$ & 38 & 7 \\
\hline 9 & NEGATIVE & 3.2 & Increased & 200,000 & $58,000,000$ & 28 & 5 \\
\hline 10 & NEGATIVE & 1.6 & Increased & 100,000 & $55,000,000$ & 0 & 5 \\
\hline 11 & NEGATIVE & 3 & Increased & 100,000 & $25,000,000$ & 5 & 6 \\
\hline 12 & NEGATIVE & 0.3 (hypoposia) & Increased & 200,000 & $46,000,000$ & 18 & 4 \\
\hline 13 & NEGATIVE & 2.6 & Normal & 100,000 & $8,000,000$ & 35 & 6 \\
\hline 14 & NEGATIVE & 3.7 & Increased & 100,000 & $23,000,000$ & 28 & 3 \\
\hline 15 & NEGATIVE & 1 (hypoposia) & Increased & 200,000 & $18,000,000$ & 22 & 2 \\
\hline
\end{tabular}

Table 3: Semen parameters for COVID-19-positive individuals in mild and moderate group.

\begin{tabular}{lrrr}
\hline Semen parameter & Mild $(\mathrm{n}=\mathbf{1 0})$ & Moderate $(\mathrm{n}=5)$ & $\mathrm{p}$-Value \\
\hline Semen volume, $\mathrm{mL}$ & $2.18 \pm 1.20$ & $2.39 \pm 0.88$ & 0.70 \\
Sperm concentration, $10^{6} / \mathrm{mL}$ & $30,200,000.0 \pm 20,801,442.26$ & $38,200,000.00 \pm 21,632,280.41$ & $7.65 \pm 0.18$ \\
PH & $7.48 \pm 0.22$ & 0.50 \\
Total sperm number, $10^{6} /$ ejaculate & $67,500,000.0 \pm 65,808,282.15$ & $89,290,000.00 \pm 79,279,708.07$ \\
Progressive motility & $45.20 \pm 14.34$ & $40.60 \pm 14.72$ & $60.60 \pm 7.08$ \\
Vitality & $66.0 \pm 11.59$ & $4.10 \pm 1.44$ & 0.50 \\
Sperm morphology & $4.0 \pm 2.34$ & 0.27 \\
Leucocytes detected, millions/mL & $200,000.0 \pm 173,205.08$ & 0.92 \\
\hline
\end{tabular}


pathological changes were observed in seminiferous tubules and Sertoli Cells of post-mortem testis specimens of COVID-19 patients [7].

It has been demonstrated that prostate luminal cells express TMPRSS2 and release it into semen as a component of prostasomes and furthermore a key role has also been shown to be that of urination and intestinal microbiota $[16,17]$. Therefore, it has been hypothesized that spermatozoa could incorporate TMPRSS2 coming from prostate secretion, consequently could be susceptible to virus entry and sexually transmit the infection [16]. However, it was reported that TMPRSS2 is not co-expressed in testicular cells or sperm [18]. In the review of Tur-Kaspa et al. [19], since both ACE2 and TMPRSS2 are essential for viral spread, it has been suggested that SARS-CoV-2 is not sexually transmitted through sperm or semen.

The possible presence of SARS-CoV-2 in the male reproductive tract could affect male fertility and both through direct damage to the spermatogenesis and through a possible inflammatory mechanism to the seminal path [20]. However, the recent literature on this issue is extremely poor and controversial; in the review published by DC Gonzalez et al. [21], the most recent and important series are discussed. In the study of Li et al. [5], the authors reported the largest number of patients examined (38 pts.) and referred a percentage rate of $16 \%(6 / 38)$ of patients with SARS-CoV-2 positivity in seminal fluid, four of which in the acute phase of the disease. In the other seven studies reported, for a total of 122 patients overall, none of them were positive [6, 9, 18, 22-24].

In our prospective study, according to these authors, we confirmed the complete absence of Covid RNA in all the 15 patients examined, regardless of the clinical stage of the disease (mild vs. moderate); furthermore, no differences were found between different seminal parameters and disease severity.

As previously stated, there are few papers in literature focused on semen quality and its possible correlations with inflammation indices in Covid patients. Holtmann et al. [20] found no significant alterations in the quality of semen in patients with SARS-CoV-2; however, in a subgroup of subjects previously undergoing antiviral therapy, semen quality had deteriorated. Ma et al. [15] published a series of 12 patients with Covid infection in which only four out of 12 patients (33\%) had altered spermiographic data. Conversely, in our experience, we confirmed a high percentage of patients with altered seminal parameters $(93.3 \%)$ with near-normal inflammation indices, including leukospermia, something which had never been reported in previously published works, thus confirming the histopathological findings observed by Yang et al. [7]. Ultrasound techniques could be applied in the future to assess any testicular damage [25]. Fever, potentially responsible for changes in the seminal picture, was observed in only three patients and no antiviral or steroid therapy was administered in this patient population. It is also interesting to observe how an increase in sperm viscosity was recorded in 12 out of 15 patients and as this modification of the seminal fluid is not related to most of the studied clinical variables; an alteration of the composition of the seminal plasma related to involvement of the seminal tract and/or oxidative stress should be considered.

Concerning the hormonal function, in a first paper published by Lin Ma et al. [4], an increase in serum LH and a lower ratio of testosterone (T) to $\mathrm{LH}$ were observed in COVID-19 patients in comparison to healthy subjects, thus suggesting damage to Leydig cells, which in turn led to reduced production of testosterone. Likewise, Yang et al. [7] observed that the number of Leydig cells in the interstitium was significantly reduced in COVID-19 patients. In our experience, no alterations in the dosages of $\mathrm{LH}$ and testosterone have been shown.

In our opinion, the major limitation of the study is represented by the relatively low number of sample patients studied, albeit in accordance with the few papers present in the literature on this issue.

Conversely, we have examined a well-defined population, predominantly military, included in a prospective study, which in the future may confirm whether the seminal alterations found are temporary or not.

\section{Conclusions}

In our study, changes in the seminal fluid were seen in almost all patients, but no particular associations were found with inflammation indices. The presence of SARS-CoV-19 viral RNA within the seminal fluid was excluded. On the other hand, the absolute majority of the patients studied exhibits alteration of the seminal fluid, also macroscopic, such as hypospermia and increased viscosity, which have not been detected in previous studies.

Research funding: None.

Competing interests: Authors state no conflict of interest. Informed consent: Informed consent was obtained from all individuals included in this study.

Ethical approval: The local Institutional Review Board has approved this study (IRB n 41025). 
Author contributions: Conceptualization: A. Zucchi, F. Scroppo, F. Gaeta; Data curation: R. Bartoletti, E. Costantini; Formal analysis: E. Illiano, F. Trama, F. Crocetto; Investigation: A. Mercuriali, M.A. Gismondo, S. Brancorsini; Methodology: R. Bartoletti, A. Zucchi; Supervision: F. Scroppo, A. Zucchi, F. Dehò; Writing original draft: A. Zucchi, F. Scroppo; Writing - review \& editing: E. Costantini, R. Bartoletti. All authors have accepted responsibility for the entire content of this manuscript and approved its submission.

\section{References}

1. Di Lorenzo G, Buonerba L, Ingenito C, Crocetto F, Buonerba C, Libroia A, et al. Clinical characteristics of metastatic prostate cancer patients infected with COVID-19 in South Italy. Oncology 2020;98:743-7.

2. Ling Y, Xu S-B, Lin Y-X, Tian D, Zhu Q-Z, Dai F-H, et al. Persistence and clearance of viral RNA in 2019 novel coronavirus disease rehabilitation patients. Chinese Med J 2020;133:1039-43.

3. Illiano E, Trama F, Costantini E. Could COVID-19 have an impact on male fertility? Andrologia 2020;52:e13654.

4. Ma L, Xie W, Li D, Song Y, Li H, Patel D-P, et al. Effect of SARS-CoV2 infection upon male gonadal function: a single center-based study. Medrxiv 2020. https://doi.org/10.1101/2020.03.21. 20037267.

5. Li D, Jin M, Bao P, Zhao W, Zhang S. Clinical characteristics and results of semen tests among men with Coronavirus disease 2019. J Am Med Assoc 2020;3:e208292.

6. Song C, Wang Y, Li W, Hu B, Chen G, Sia P, et al. Absence of 2019 novel coronavirus in semen and testes of COVID-19 patients. Biol Reprod 2020;103:4-6.

7. Yang M, Chen S, Huang B. Pathological findings in the testes of COVID-19 patients: clinical implications. Eur Urol Focus 2020;6: 1124-9.

8. Paoli D, Pallotti F, Colangelo S, Basilico F, Mazzuti I, Turriziani O, et al. Study of SARS-CoV-2 in semen and urine samples of a volunteer with positive naso-pharyngeal swab. J Endocrinol Invest 2020;43:1819-22.

9. Guo L, Zhao S, Li W, Wang Y, Li L, Jiang S, et al. Absence of SARSCoV-2 in semen of a COVID-19 patient cohort. Andrology 2021;9: 42-7.

10. Clinical Management in Covid-19 (interim guidance 27 may 2020) (c) World Health Organization 2020. Some rights reserved. This work is available under the CC BY-NC-SA 3.0 IGO licence. WHO reference number: WHO/2019-nCoV/clinical/2020.5.

11. WHO laboratory manual for the examination and processing of human semen, 5th ed. WHO; 2010.
12. Wrapp D, Wang N, Corbett KS, Goldsmith JA, Hsieh CL, Abiona O, et al. Cryo-EM structure of the 2019-nCoV spike in the prefusion conformation. Science 2020;367:1260-3.

13. Chen Y, Guo Y, Pan Y, Zhao ZJ. Structure analysis of the receptor binding of 2019-nCoV. Biochem Biophys Res Commun 2020;525: 135-40.

14. Shastri A, Wheat J, Agrawal S, Chaterjee N, Pradhan K, Goldfinger M, et al. Delayed clearance of SARS-CoV2 in male compared to female patients: high ACE2 expression in testes suggests possible existence of gender-specific viral reservoirs. Medrxiv 2020. https://doi.org/10.1101/2020.04.16.20060566.

15. Hoffmann M, Kleine-Weber H, Schroeder S, Krüger N, Herrler T, Erichsen S, et al. SARS-CoV-2 cell entry depends on ACE2 and TMPRSS2 and is blocked by a clinically proven protease inhibitor. Cell 2020;181:271-80.e8.

16. Chen YW, Lee MS, Lucht A, Chou FP, Huang W, Havighurst TC, et al. TMPRSS2, a serine protease expressed in the prostate on the apical surface of luminal epithelial cells and released into semen in prostasomes, is misregulated in prostate cancer cells. Am J Pathol 2010;176:2986-96.

17. Crocetto F, Boccellino M, Barone B, Di Zazzo E, Sciarra A, Galasso G, et al. The crosstalk between prostate cancer and microbiota inflammation: nutraceutical products are useful to balance this interplay? Nutrients 2020;12:2648.

18. Pan F, Xiao X, Guo J, Song Y, Li H, Patel DP, et al. No evidence of severe acute respiratory syndrome-coronavirus 2 in semen of males recovering from coronavirus disease 2019. Fertil Steril 2020;113:1135-9.

19. Tur-Kaspa I, Tur-Kaspa T, Hildebrand G, Cohen D. COVID-19 may affect male fertility but is not sexually transmitted: a systematic review. F S Rev 2021;2:140-9.

20. Napolitano L, Barone B, Crocetto F, Capece M, La Rocca R. The COVID-19 pandemic: is it a wolf consuming fertility? Int J Fertil Steril 2020;14:159-60.

21. Gonzalez DC, Khodamoradi K, Pai R, Guarch K, Connelly ZM, Ibrahim E, et al. A systematic review on the investigation of SARS-CoV-2 in semen. Res Rep Urol 2020;12:615-21.

22. Ma L, Xie W, Li D, Ling Ma, Xie W, Li D, et al. Effect of SARS-CoV-2 infection upon male gonadal function: a single center-based study. J Med Virol 2020;93:456-62.

23. Rawlings SA, Ignacio C, Porrachia M, Du P, Smith DM, Chaillon A. No evidence of SARS-CoV-2 seminal shedding despite SARS-CoV2 persistence in the upper respiratory tract. Open Forum Infect Dis 2020;7:1-3.

24. Kayaaslan B, Korukluoglu G, Hasanoglu I, Kalem AK, Eser F, Akinci E, et al. Investigation of SARS-CoV-2 in semen of patients in the acute stage of COVID-19 infection. Urol Int 2020;104:678-83.

25. Illiano E, Trama F, Ruffo A, Romeo G, Riccardo R, Crocetto F, et al. Testicular shear wave elastography in oligo-asthenoteratozoospermic individuals: a prospective case-control study. Int Urol Nephrol 2021;53:1773-83. 